\title{
In the Front Line of World Science
}

\author{
A.V. Zelenin and V.L. Karpov
}

The creation and organization of the Institute of Molecular Biology (in its first six years it was called the Institute of Radiation and Physicochemical Biology, Academy of Sciences of the USSR) is forever connected with the name of Vladimir Alexandrovich Engelhardt, one of the most outstanding biochemists and molecular biologists of the $20^{\text {th }}$ century. Vladimir Alexandrovich won broad fame and international acclaim as far back as the 1930s for discovering oxidative (respiratory) phosphorylation with the participation of ATP. In the beginning of the 1940s, Vladimir Alexandrovich earned fame again, when he and his wife Milicia Nikolaevna Lyubimova discovered the fermentation activity of myosin protein, which allowed him to suggest a theory about the combination of the structure and functions of biological compounds on the level of individual molecules. This scientific body of work became part of a goldmine of science, while Vladimir Alexandrovich began to be justifiably referred to as one of the founders of molecular biology in our country.

\section{ON THE SEMICENTENARY OF THE ENGELHARDT INSTITUTE OF MOLECULAR BIOLOGY, RUSSIAN ACADEMY OF SCIENCES}

In the middle the $1950 \mathrm{~s}$, Vladimir Alexandrovich progressed up the career ladder and became an AcademicianSecretary of the Biological Research Branch, Academy of Sciences of the USSR. Needless to say, he had to immediately join in the reconstruction and consolidation of Russian experimental biology and genetics, which were almost completely in ruins. The most important stage in that process was, in his opinion, the creation of the first specialized Russian molecular biological institute. Vladimir Alexandrovich managed to build that institute with the unwavering support of A.N. Nesmeyanov, president of the Academy of Sciences of the USSR, and a group of outstanding physicists such as I.V. Kurchatov, P.L. Kapitsa, and I.E. Tamma. The Resolution on the Creation of a New Molecular Biological Institute was adopted in April of 1957 by the Presidium of the Academy of Sciences of the USSR, but in fact the institute was launched two years later.

V.A. Engelhardt managed to attract a series of brilliant researchers to the Institute of Molecular Biology (IMB), including biochemists A.E. Brownstein and A.A. Baev, cytogenetics specialist A.A. Prokofieva-Belgovsky, cell biologist M.N. Maisel, biophysicist M.V. Folkenstein, physicist L.A. Tumerman, and crystallographer N.S. Andreeva. At the same time, many young researchers interested in the new science and graduates of different universities also joined the institute.

The young generation of leaders included G.P. Georgiev, A.D. Mirzabekov, A.A. Kraevsky, R.M. Khomutov, and L.L. Kiselev. As a result, in a short period of time, just as the institute received its present name, it had acquired a complete, actively working team involved in investigating a definite range of issues. The researchers investigated the structures and biosynthesis mechanisms of nucleic acids and the primary and space structures of proteins and their complexes, as well as the mechanisms of their functioning on the molecular level in in vitro systems, viruses, and cells. That range of problems to tackle predetermined the areas of the institute's activity for many years, though it underwent intensive development and significant modification later on.

The institute became well-known in Russia and abroad. In this connection, it is essential to note first the interpretation of the primary structure of the valine transfer RNA carried out under the guidance of Baev. It was the first structure of biopolymer interpreted in our country and the sixth primary structure of tRNA in the world. In the following years, researchers successfully studied information transfer in eukaryote cells, the mechanisms of gene expressions regulation, and the nature of the mobile genetic elements of drosophila; they also interpreted the chromatin structure and established with high resolution the tertiary structure of pepsin and some other proteins. Great progress was noted in the formulation of the biochemical grounds of protein biosynthesis and the chemical grounds of biocatalysis and the physics of biopolymers, as well as for the creation of new site-directed inhibi- 


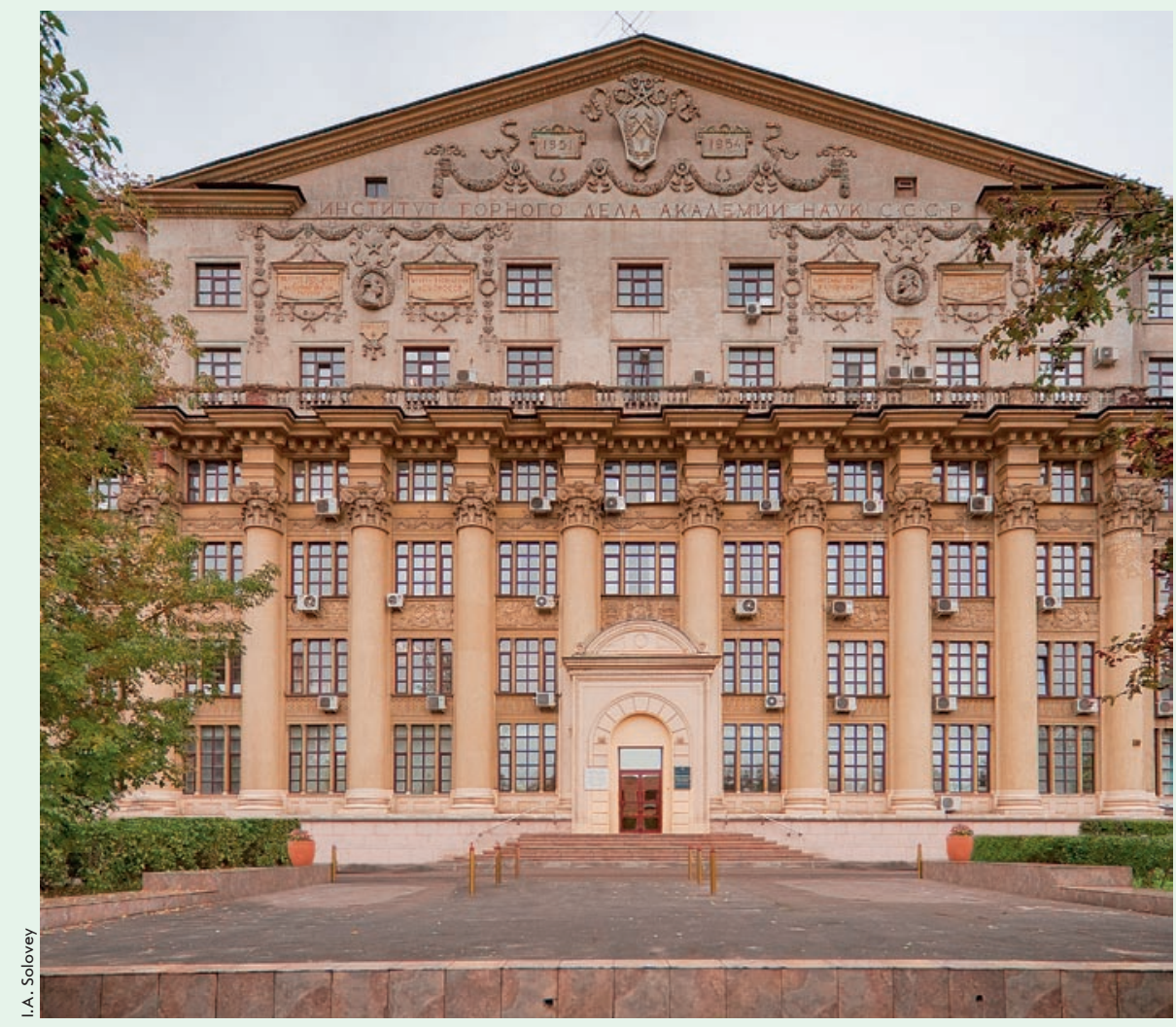

tors of biological processes. The drug Phosphaside (NIKAVIR), created under the guidance of Kraevsky, became a very important drug that prolongs the life of those suffering from immunodeficiency disorder. Research by a team working under the guidance of Prokofieva-Belgovsky paved the way for medicogenetic service development in our country.

In the late 1980s and early 1990 s, the institute underwent significant restructuring. A modern instrumental base was created to intensify work in the sphere of cell molecular biology; investigations in new directions such as immunooncology and immunogenetics were started; and, finally, Mirzabekov initiated the development of biological microchip technology. These investigations have continued to the present day. The bilateral Russian-American Laboratory, which linked the Institute of Molecular Biology in Moscow and the Argonne National Laboratory in Chicago (one of the leading centers in the development of atomic power and for the solution of the most important problems of fundamental science in the United States), gained distinction as well. That inter- national team managed to create the technology of gel microchips on the basis of IMB development work, which is becoming more and more important in the molecular diagnostics of infectious and oncological diseases.

The institute created by V.A. Engelhardt was based on the principle of the three pillars of physics, chemistry, and biology, which formed the basis of molecular biology at that time, although today the talk is about specialists of a new profile, so-called molecular biologists who use the principles and methods of the above-mentioned sciences in their work.

Almost immediately, from the date of its inception, the institute became the center of "crystallization" of the Russian researchers engaged in research and interested in molecular biology. The numerous meetings, conferences, and seminars organized by the institute encouraged that process. As a consequence, the institute took a leading place among the establishments that spearheaded the regeneration of science in our country. It is essential to note the important role that the "Revertase" program and the Soviet (and later Russian) "Human Genome" program played in the development of Russian science.

Today, the main areas of scientific activity at the institute are as follows:

- structure and function of nucleic acids, proteins, and their complexes;

- structural and functional genomics;

- molecular biology of cell;

- molecular immunology;

- bionanotechnologies and the fundamentals of medical diagnostics.

The researchers at the institute have carried out a range of research that has contributed significantly to the development of international molecular biology and spurred current ideas about the physicochemical elements of living systems. It is impossible to consider the whole wide range of investigations carried out at the IMB in this brief review: therefore, let's turn our attention only to the most important issues.

Really cutting-edge discoveries are made at the intersection of disciplines such as immunology, molecular genetics, bioorganic chemistry, biotechnology, and medicine. The focus of interest and primary fields in this direction include physiological functions; the mechanisms of the action and regulation of cytokines; the so-called protein mediators of the immune system; the mechanisms activating cytokines, including the whole chain of signal transfer beginning from the activation of the genetic immunity receptors; and the protective and pathological properties of the TNF family (tumor necrosis factor) cytokines. In particular, researchers have created unique living systems such as mice with the TNF gene silenced in some cells of their immune systems [1] and mice with silenced lymphotoxin genes [2]. Using these mice made it possible to obtain new important results in physiology and medicine [3-5]. The applied aspects of these investigations are related to the characteristics of new human cancer antigens and the possibility of using them for diagnostics and the monitoring of oncological diseases, as well as to create new drugs.

Researchers at the institute have revealed the important prophylactic role played by the p53 gene, which is able to function in a cell as an antioxidant and to decrease the level of oxygen radicals. This effect is achieved thanks to the p53-dependent adaptation of 
antioxidant protective systems that save DNA cells from damage caused by physiological stress. Hence, the p53 gene significantly slows the mutation process and, in doing so, prevents malignant diseases and premature aging $[6,7]$. The prototype of a new antitumor drug has been created: a small RETRA molecule which selectively kills tumor cells thanks to the activation of the p73 protein [8]. A team at the same laboratory has discovered the fourth nuclear RNA polymerase which performs the partial transcription of mRNA in animal and human cells [9].

Active and successful investigations are ongoing in the sphere of gene transcription regulation by the example of drosophila. Researchers have discovered a new protein complex of drosophila that is related to nuclear pores and responsible for $\mathrm{mRNA}$ export from the nucleus. It has been established that the $\mathrm{E}(\mathrm{y}) 2$ transcription factor, which is a component of this complex, is present in the multiprotein SAGA transcription complex and provides a connection between the transcription and export of mRNA of actively functioning genes; i.e., the researchers have discovered a new mechanism controlling effective gene expression [10-12]. It has been established that the TRF2 transcription activator, which contains a domain homological to the promoter-binding domain of the main TBP transcription activator, plays an important role in maintaining the chromatin structure and its condensation [13].

Investigations in the area of translation mechanisms, traditionally a field of success for the institute, are in progress. In recent years, researchers have developed a system that makes it possible to analyze in vitro the contribution of any component of the translation complex at different stages of protein synthesis. It has been established that the GTF hydrolysis precedes the peptidyl-tRNA hydrolysis upon translation termination, while eRF3 significantly accelerates this reaction [14]. In the structure of termination factors of first-class bacteria, the eukaryote and archaeon $\mathrm{N}$-domain are responsible for recognizing the mRNA stop codon, the $\mathrm{C}$-domain is responsible for binding with eRF3, and the M-domain contains a universal GGQ-motive necessary for peptidyl-tRNA hydrolysis in ribosome.
The eRF3 protein has been found to be characterized by GTF activity, which depends on eRF1 and ribosomes, and to form an in vitro complex with eRF1. The role of guanylic nucleotides in the functioning of the elongation factor of the EF-G translation has been determined [15, 16].

The researchers at IMB have discovered a new class of mobile genetic elements called "Penelope-like elements" [17]. Representatives of this quite ancient class are present in hundreds of animal species, from rotifers to fish and reptiles. The Penelope element has been established to be responsible for the hybrid dysgenesis syndrome of Drosophila virilis. The researchers have offered a model of chromosomal speciation, which assigns a leading role to mobile elements that are able, under certain conditions, to cause the "explosion" of mutability.

Work in the sphere of bioinformatics has developed intensively: for instance, researchers have revealed the relation between genome polymorphism phenomena and alternative splicing, which provides multiplicity of the human proteome [18]. A computational method for predicting the substitution of amino acids in proteins has been designed, and a database of the functional protein polymorphisms in the human genome has been created (http://www.snp.imb.ac.ru) [19].

The results of the fundamental scientific research of IMB researchers are used in applied fields. The technology of gel biochips initiated and elaborated under the guidance of Academician Mirzabekov was developed as an innovative product, was patented, and then spread to medical practice, where it helps carry out express diagnostics of socially important infectious, oncological, cardiovascular, and inherited diseases, as well as identify the special danger of infections and biotoxins [20, 21]. A pilot production, where several thousands of biochips were produced every day, was organized. For the Russian Federal Service for the Supervision of Public Health and Social Development, the researchers have developed and registered a biochip analyzer and a range of biochip-based test-systems for different applications in medical diagnostics, including a test-system for the genetic typing of 36 hepatitis $\mathrm{C}$ sub- types (International Application for the Patent PCT/RU2007/000438, in partnership with the University and Hospital of Toulouse) [22]. Moreover, they have developed a method for quantitatively estimating proteins on the basis of a combination of biochip technology and time-of-flight mass spectrometry [23].

The biochip-based test-systems make it possible to determine and analyze the sensitivity of tuberculosis microbacteria to medical drugs; viruses of human immunodeficiency (HIV-1); hepatitis B and C (36 subtypes); influenza A (30 subtypes, including bird flu $\mathrm{H} 5 \mathrm{~N} 1$ and swine flu H1N1); herpetic fever (2 subtypes); pox (6 subtypes); bacillus anthracis; protein markers of oncological diseases (12 tumor markers) and biotoxins (9 types); chromosome aberrations that cause 13 types of leucosis; individual pharmacogenetic status; one's genetic disposition to certain oncological, cardiovascular, and inherited diseases; and personal genetic markers (18 markers which determine more than 1,000 variants of the human genome). Biochips for establishing the causative agent of tuberculosis and identifying its drug-resistant forms allows doctors to reduce the time needed for analysis from 6-10 weeks to a few hours and to choose an adequate treatment quickly. Biochip diagnostics is applied in more than 30 antituberculosis centers in Russia and countries of the CIS. Biochips for typing chromosome aberrations that cause oncological diseases in blood are certified and used for prognosis updating and selecting a treatment strategy at the Russian Children's Health Clinic (Moscow), where samples from 18 regional hematological centers of the Russian Federation are analyzed.

The researchers have created a method of PCR conduction in biochip cells on a real-time basis that allows them not only to detect pathogenic bacteria, viruses, and cancer cells in a sample, but also to simultaneously estimate their number in all samples [24]. An automated device based on replaceable modules is being developed to extract trace amounts of nucleic acids from biological samples. The following integration of this module and system for PCR conduction in biochip cells with real-time detection will lead to the ap- 
pearance of a radically new device: the so-called laboratory-on-chip. The appearance of such a device will exclude contact between the object being analyzed and the external environment, which will significantly decrease the probability of personnel infection and contamination.

The Russian Academy of Sciences, along with the Institute of Spectroscopy, has developed analytical systems based on portative dichrometers, which help to detect different compounds in the environments analyzed, and applied for nine patents. Nanoconstructions developed on the basis of liquid-crystalline dispersions of nucleic acids may be used as atom-carriers of heavy elements for neutron-capturing therapy of tumor diseases.

The applied work also includes investigations of the genetic fingerprinting used in the genetic identification of the remains of Nicholas II and the members of his family. The researchers proceeded to successfully develop antivirals based on the original Russian anti-HIV-drug NIKAVIR. A range of new inhibitors of hepatitis $\mathrm{C}$ virus replication have been obtained. An analogue of the antiherpetic drug Acyclovir, which allows the replication of strains of the herpes virus resistant to Acyclovir, has been created [25].

For achievements in the sphere of fundamental and applied science, researchers of the Institute of Molecular Biology, Russian Academy of Sciences, have been honored at different times with two Lenin Prizes and eight State Prizes, the Demidov Prize, the Prize of the Federation of European Biochemical Societies, and numerous other prizes and medals. Young scientists have received many Lenin Komsomol prizes and have also been honoured with the State Prize of the Russian Federation in the Sphere of Science and Technology.
In connection with the jubilee of the Institute, foreign scientists have highly rated the contribution of IMB to the development of modern molecular biology; in particular, they have noted that the Engelhardt Institute is famous for its talented researchers and that even in its most difficult years its researchers had continued to believe in the universality of scientific knowledge, ignoring state boundaries and managing to contribute greatly to the development of molecular biology [26].

The Institute of Molecular Biology is celebrating its sixth decade as a firstclass scientific establishment that has everything needed to conduct investigations in the sphere of molecular and cellular biology on an international level. Its scientific research is supported by many Russian and foreign grants, while its substantial number of young scientists allow us to face the future with hope and confidence.
REFERENCES:

1. Grivennikov S.I., Tumanov A.V., Liepinsh D.J., Kruglov A.A., Marakusha B.I., Shakhov A.N., Murakami T., Drutskaya M.S., Förster I., Clausen B.E., Tessarollo L., Ryffel B., Kuprash D.V., Nedospasov S.A. 2005. Distinct and non-redundant in vivo functions of TNF produced by $\mathrm{T}$ cells and macrophages/ neutrophils: protective and deleterious effects. Immunity. 22. 93-104

2. Liepinsh D.J., Grivennikov S.I., Lagarkova M.A., Drutskaya M.S., Klarmann K.D., Lockett S.J., McAuliffe M., Tessarollo L., Keller J.R., Kuprash D.V., Nedospasov S.A. 2006. Novel lymphotoxin alpha knockout mice with unperturbed TNF expression: reassessing LTalpha biological functions. Mol Cell Biol. 26. 4214-4225.

3. Cui C.-Y., Hashimoto T., Grivennikov S.I., Piao Y., Nedospasov S.A., and Schlessinger D. 2006. Ectodysplasin activates the lymphotoxin-beta pathway for hair follicle differentiation. Proc Natl Acad Sci USA. 103. 9142-9147.

4. Welniak L.A., Kuprash D.V., Tumanov A.V., Panoskaltsis-Mortari A., Blazar B.R., Sun K., Nedospasov S.A., and Murphy W.J. 2006. Peyer's patches are not required for acute lethal graft-versus-host disease after myeloablative conditioning and murine allogeneic bone marrow transplantation. Blood. 107. 410-412.

5. Tumanov A.V., Koroleva E.P., Christiansen P.A., Khan M.A., Ruddy M.J., Burnette B., Papa S., Franzoso G., Nedospasov S.A., Fu Y.X., Anders R.A. 2009. T cell-derived lymphotoxin regulates liver regeneration. Gastroenterology. 136. 694-704.

6. Sablina A.A., Budanov A.V., Ilyinskaya G.V., Agapova L.S., Kravchenko J.E., Chumakov P.M. 2005. The antioxidant function of the p53 tumor suppressor. Nat. Medicine. 11 1306-1313.

7. Budanov A.V., Sablina A.A., Feinstein E., Koonin E.V., Chumakov P.M. 2004.

Regeneration of peroxiredoxins by p53-regulated sestrins, homologs of bacterial AhpD. Science. 304. 596-600.

8. Kravchenko J.E., Ilyinskaya G.V., Komarov P.G., Agapova L.S., Kochetkov D.V., Strom E., Frolova E.I., Kovriga I., Gudkov A.V., Feinstein E., Chumakov P.M. 2008. Small molecule RETRA suppresses mutant p53-bearing cancer cells through a p73 dependent salvage pathway. Proc. Natl. Acad. Sci. USA. 105.6302-6307.

9. Kravchenko J.E., Rogozin I.B., Koonin E.V., Chumakov P.M. 2005. Transcription of mammalian mRNAs by a novel nuclear RNA polymerase of mitochondrial origin. Nature. 436. 735-739.

10. Shidlovskii Y.V., Krasnov A.N., Nikolenko J.V., Lebedeva L.A., Kopantseva M., Ermolaeva M.A., Ilyin Yu.V., Nabirochkina E.N., Georgiev P.G. and Georgieva S.G. 2005. A novel multidomain transcription coactivator SAYP can also repress transcription in heterochromatin. EMBO Journal. 24. 97-107.

11. Kurshakova M., Krasnov A., Kopytova D., Shidlovsky Y., Nikolenko J., Nabirochkina E., Splender D., Schultz P., Tora L., Georgieva S. 2007. SAGA and a novel Drosophila export complex anchor efficient transcription and mRNA export to NPC. EMBO Journal. 26. 4956-4965.

12. Krasnov A., Kurshakova M., Ramensky V., Mardanov P., Nabirochkina E., Georgieva S. 2005. A retrocopy of a gene can functionally displace the source gene in evolution. Nucleic Acids Res. 33. 6654-6661.
13. Kopytova D., Krasnov A., Kopantceva M., Nabirochkina E., Nikolenko J., Kurshakova M., Lebedeva L., Korochkin L., Tora L., Georgiev P., Georgieva S. 2006. The two isoforms of Drosophila TRF2 are essential for embryonic development, premeiotic chromatin condensation and proper differentiation of germ cells of both sexes. Mol. Cell. Biol. 26. 7492-7505.

14. Alkalaeva E.Z., Pisarev A.V., Frolova L.Yu., Kisselev L.L., Pestova T.V. 2006. In vitro reconstitution of eukaryotic translation reveals cooperativity between release factors eRF1 and eRF3. Cell. 125. 1125-1136.

15. Mitkevich V.A., Kononenko A.V., Petrushanko I.Yu., Yanvarev D.V., Makarov A.A., Kisselev L.L. 2006. Termination of translation in eukaryotes is mediated by the quaternary eRF1 $\cdot \mathrm{eRF} 3 \cdot \mathrm{GTP} \cdot \mathrm{Mg}^{2+}$ complex. The biological roles of eRF3 and prokaryotic RF3 are profoundly distinct. Nucleic Acids Res. 34. 3947-3954.

16. Hauryliuk V., Mitkevich V.A., Eliseeva N.A., Petrushanko I.Yu, Ehrenberg M., Makarov A.A. 2008. The pretranslocation ribosome is targeted by GTP-bound EF-G in partially activated form. Proc. Natl. Acad. Sci. USA. 105. 15678-15683.

17. Pyatkov K.I., Arkhipova I.R., Malkova N.V., Finnegan D.J., Evgen'ev M.B. 2004 Reverse transcriptase and endonuclease activities encoded by Penelope-like retroelements. Proc. Natl. Acad. Sci.USA. 101. 14719-14724.

18. Ramensky V.E, Nurtdinov R.N, Neverov A.D, Mironov A.A, Gelfand M.S. 2008. Positive selection in alternatively spliced exons of human genes. Am J Hum Genet. 83. 94-98. 19. Sunyaev S., Kondrashov F.A., Bork P., Ramensky V. 2003. Impact of selection, mutation rate and genetic drift on human genetic variation. Hum Mol Genet. 12. 3325-3330.

20. Mikhailovich V., Gryadunov D., Kolchinsky A., Makarov A.A., and Zasedatelev A. 2008. DNA microarrays in the clinic: infectious diseases. Bioessays. 30. 673-682.

21. Rubina A.Yu., Kolchinsky A., Makarov A.A., Zasedatelev A.S.. 2008. Why 3D? GelBased Microarrays in Proteomics. Proteomics. 8. 817-831.

22. Gryadunov D.A., Mikhailovich V.M., Nicot F., Dubois M., Zasedatelev A.S., Izopet J. Method for identifying the genotype and subtype of hepatitis $\mathrm{C}$ virus on a biological microchip. International Application Number PCT/RU2007/000438.

23. Darii E., Lebeau D., Papin N., Rubina A.Y., Stomakhin A., Tost J., Sauer S., Savvateeva E., Dementieva E., Zasedatelev A., Makarov A.A. and Gut I.G. Quantification of target proteins using hydrogel antibody arrays and MALDI time-of-flight mass spectrometry (A2M2S). 2009. New Biotechnology. (in press).

24. Khodakov D.A., Zakharova N.V., Gryadunov D.A., Filatov F.P., Zasedatelev A.S, Mikhailovich V.M. 2008. An oligonucleotide microarray for multiplex real-time PCR identification of HIV-1, HBV, and HCV. Biotechniques. 44. 241-248.

25. Karpenko I.L., Jasko M.V., Andropova V.L., Ivanov A.V., Kukhanova M.K., Galegov G.A., Skoblov Y.S. 2003. Synthesis and antiherpetic activity of acyclovir phsphonates. Nucleosides Nucleotides Nucleic Acids. 22. 319-328.

26. Jubilee brochure devoted to semicentenary of the Engelhardt Institute of Molecular Biology, Russian Academy of Sciences. 